\title{
RELATIONSHIP BETWEEN DOOR-TO-BALLOON TIME AND CLINICAL EXPERIENCE LEVEL OF EMERGENCY DEPARTMENT PHYSICIANS
}

\author{
Ercan AYDIN ${ }^{1}$, Emre YILMAZ², and Salih ŞAHINKUŞ ${ }^{3}$ \\ ${ }^{1}$ Trabzon Ahi Evren Thoracic and Cardiovascular Surgery Training and Research Hospital \\ ${ }^{2}$ Giresun Universitesi Tip Fakultesi \\ ${ }^{3}$ Sakarya Üniversitesi Eğitim Ve Araştırma Hastanesi
}

January 7, 2021

\begin{abstract}
Background: This study aimed to investigate the relationship between the experience level of physicians who initially make a clinical diagnosis of patients with ST segment elevation myocardial infarction in the emergency department and door-to-balloon time (DBT). Material and methods: Between January and December 2018, the research group was selected randomly among 522 patients with ST elevation myocardial infarction who were immediately treated in the catheter laboratory. Angiography images were monitored from the patients' records in the catheter laboratory. The time of admission to the emergency room was obtained using the hospital registration system. The experience level of physicians who initially clinically diagnosed patients in the emergency department was divided into three groups: medical practitioner (who did not receive emergency training), assistant physician (undergoing emergency medicine training), and emergency medicine specialist. Results: The study included 522 patients who underwent primary percutaneous intervention due to ST segment elevation myocardial infarction. The mean age was lower, and cardiogenic shock and mortality rates were lower in the group with DBT $<60 /$ min compared with the group with $\mathrm{DBT}>60 / \mathrm{min}$. In the expert group, the mean DBT was lower, but the cardiogenic shock and mortality rates were higher $(\mathrm{p}<0.05)$. Conclusions: The duration of DBT decreases as the experience level of the emergency physician increases, but randomization is required to determine its clinical benefit
\end{abstract}

\section{RELATIONSHIP BETWEEN DOOR-TO-BALLOON TIME AND CLINICAL EXPERI- ENCE LEVEL OF EMERGENCY DEPARTMENT PHYSICIANS}

\section{Abstract}

Background : This study aimed to investigate the relationship between the experience level of physicians who initially make a clinical diagnosis of patients with ST segment elevation myocardial infarction in the emergency department and door-to-balloon time (DBT).

Material and methods: Between January and December 2018, the research group was selected randomly among 522 patients with ST elevation myocardial infarction who were immediately treated in the catheter laboratory. Angiography images were monitored from the patients' records in the catheter laboratory. The time of admission to the emergency room was obtained using the hospital registration system. The experience level of physicians who initially clinically diagnosed patients in the emergency department was divided into three groups: medical practitioner (who did not receive emergency training), assistant physician (undergoing emergency medicine training), and emergency medicine specialist.

Results: The study included 522 patients who underwent primary percutaneous intervention due to ST segment elevation myocardial infarction. The mean age was lower, and cardiogenic shock and mortality 
rates were lower in the group with $\mathrm{DBT}<60 /$ min compared with the group with $\mathrm{DBT}>60 / \mathrm{min}$. In the expert group, the mean DBT was lower, but the cardiogenic shock and mortality rates were higher $(\mathrm{p}<0.05)$.

Conclusions: The duration of DBT decreases as the experience level of the emergency physician increases, but randomization is required to determine its clinical benefit.

Keywords: ST segment elevation myocardial infarction, door-to-balloon time, angiography, primary coronary intervention, emergency physician

\section{Key messages}

What is already known on this subject : Door-to-balloon time (DBT) is an important parameter affecting the prognosis in patients requiring primary percutaneous intervention. Many studies have been conducted to define risk factors affecting the duration of DBT and to modify these risk factors to shorten the duration of DBT.

What this study adds : However, there is no study in the design that evaluates the effects of physicians working in emergency units on the change of DBT duration by physician experience and knowledge categories. The aim of our study is to define a new risk factor that affects the duration of DBT and to produce a solution proposal for this risk factor.

\section{Introduction}

ST elevation myocardial infarction (STEMI) is a life-threatening clinical condition in which reperfusion must be quickly achieved and treated [1].Primary percutaneous coronary intervention (PPCI) is the treatment of choice in patients with STEMI if it can be performed on time [2].The purpose of perfusion therapy is to provide immediate reperfusion. Door-to-balloon time (DBT) is defined as the time from the first medical contact to balloon angioplasty and should not exceed $60 \mathrm{~min}$ if a catheter laboratory is available [3].

Some factors affect the care of patients with acute coronary syndrome in the emergency department. Examples include triage of patients, duration of electrocardiography (ECG) monitoring and evaluation, start time of emergency treatment protocols, consultation times, and distance of the catheter laboratory from the emergency room. However, it is also important to investigate the relationship between the clinical experience level of emergency room workers and the duration of primary percutaneous coronary intervention in patients with acute STEMI. The effect of the emergency room physician's level of experience on the DBT has not been seen in the literature.

This study aimed to examine the effect of this period on the level of clinical experience of emergency department physicians and on DBT and in-hospital mortality in patients, which may affect compliance with existing diagnosis and treatment guidelines.

\section{Material and methods}

This study included 522 patients who underwent primary PCI due to STEMI were included. The data of patients who applied to Sakarya University Education and Research Hospital between January and December 2018 were retrospectively analyzed. Between January and December 2018, the research group was selected randomly among 522 patients STEMI patients who were treated in the catheter laboratory within a 1-year period. The relationship between the experience level of the physician who initially clinically diagnosed the patient in the emergency department and the patient's DBT and the effect of this relationship on in-hospital clinical events and mortality were investigated.

Demographic features, in-hospital complications, and mortality results were obtained from records of the in-hospital system. Angiography images were monitored from the records of the patients in the catheter laboratory. The time of admission to the emergency room was obtained using the hospital registration system. In our study, DBT was defined as the time from the first medical contact in the emergency room to the passing the guidewire from the culprit artery. In addition, desk balloon time was considered as the period between the patient's entrance to the catheter lab and passing the guidewire from the culprit artery. 
The experience level of physicians who initially clinically diagnosed patients in the emergency department was divided into three groups: medical practitioner (who did not receive emergency training), assistant physician (undergoing emergency medicine training), and emergency medicine specialist.

The emergency unit of our hospital consists of 3 sections: green, yellow and red areas. The red area is the unit where life-threatening patients are followed in case of shock or pre-shock, and 'emergency medicine specialist' physicians work. In the yellow and green areas, all three physician groups work alternately. Medical practitioner: consists of physicians with 1-5 years of experience in the emergency department. Assistant physician: emergency unit experience ranges from 1 to 5 years and consists of physicians who are trained in emergency medicine residency. Emergency medicine specialist: consists of physicians who have completed emergency medicine training and have $>5$ years of emergency unit experience. Patients who apply to the emergency department of our hospital with the complaints of "chest pain", "chest pressure" or "chest tightness" are primarily directed to the yellow area and ECG is obtained quickly. This hospital policy to shorten the acute coronary syndrome 'Door to ECG time' ensures that STEMI patients are randomly distributed to emergency department physicians as much as possible.

The study protocol was designed in accordance with the principles of the declaration of Helsinki, and the approval (no: $715224473 / 050.01 .04 / 395$ ) of the ethics committee was obtained.

\section{Statistical analysis}

Statistical analysis was performed using SPSS 24.0 software. Categorical and continuous variables were expressed as numbers or percentages and mean standard deviation, respectively. The Kolmogorov-Smirnov test was used to determine the consistency of parameters to normal distribution, and the chi-squared and Fisher exact tests were used to compare categorical variables. Continuous data consisting of independent measurements and normal distribution were analyzed using t test and one-way analysis of variance. Statistical significance was determined if $\mathrm{p}<0.05$.

\section{Results}

In 2018, 522 patients who applied to primary PCI due to STEMI were included in the study, and the mean DBT was determined as $88 \pm 29 \mathrm{~min}$. The DBT $<60 \mathrm{~min}$ and DBT $>60$ min groups were composed of $315(\mathrm{DBT}=38 \pm 12 \mathrm{~min})$ and $207(\mathrm{DBT}=105 \pm 35 \mathrm{~min})$ patients, respectively. The demographic and clinical variables of the two groups are shown inTable 1 .

Table 1. Comparison of baseline characteristics and clinical outcomes of patients with or without DBT $<60$ min.

\begin{tabular}{llll}
\hline Parameters & DBT $<60(\mathrm{n}=321)$ & DBT $>60(\mathrm{n}=201)$ & $\mathrm{p}$ \\
\hline Male, n (\%) & $267(83.2 \%)$ & $156(77.6 \%)$ & 0.114 \\
Female, n (\%) & $54(16.8 \%)$ & $45(22.4 \%)$ & \\
Age, years & $60.2 \pm 12.3$ & $62.4 \pm 13.3$ & $\mathbf{0 . 0 4 6}$ \\
Current smoker, n (\%) & $169(52.7 \%)$ & $79(39.6 \%)$ & $<\mathbf{0 . 0 0 1}$ \\
Hypertension, n (\%) & $123(38.3 \%)$ & $89(44.3 \%)$ & 0.177 \\
Diabetes mellitus, n (\%) & $63(19.6 \%)$ & $55(27.4 \%)$ & $\mathbf{0 . 0 4 0}$ \\
Hyperlipidemia, n (\%) & $56(17.4 \%)$ & $24(11.9 \%)$ & 0.089 \\
CAD history, n (\%) & $58(18.1 \%)$ & $36(17.9 \%)$ & 0.964 \\
Prior stent, n (\%) & $43(13.4 \%)$ & $22(10.9 \%)$ & 0.409 \\
Prior CABG, n (\%) & $10(3.1 \%)$ & $8(4 \%)$ & 0.598 \\
CVD history, n (\%) & $11(3.4 \%)$ & $3(1.4 \%)$ & 0.183 \\
Stent implantation, n (\%) & $299(93.1 \%)$ & $162(80.6 \%)$ & $<\mathbf{0 . 0 0 1}$ \\
SYNTAX score, n & $13.5 \pm 6.4$ & $16.3 \pm 7.8$ & 0.194 \\
EF, \% & $43.1 \pm 10.1$ & $44.2 \pm 10.2$ & 0.503 \\
Spontaneous recanalization,n $(\%)$ & $30(9.3 \%)$ & $57(28.4 \%)$ & $<\mathbf{0 . 0 0 1}$ \\
Arrhythmia, n (\%) & $37(11.5 \%)$ & $24(11.9 \%)$ & 0.886
\end{tabular}




\begin{tabular}{llll}
\hline Parameters & $\mathrm{DBT}<60(\mathrm{n}=321)$ & $\mathrm{DBT}>60(\mathrm{n}=201)$ & $\mathrm{p}$ \\
\hline Contrast nephropathy, n (\%) & $16(5 \%)$ & $10(5 \%)$ & 0.996 \\
Cardiogenic shock, n (\%) & $27(8.4 \%)$ & $30(14.9 \%)$ & $\mathbf{0 . 0 2 0}$ \\
Exitus, n (\%) & $23(7.2 \%)$ & $28(13.9 \%)$ & $\mathbf{0 . 0 1 1}$ \\
\hline
\end{tabular}

DBT, door-to-balloon time; CAD, coronary artery disease; CABG, coronary artery bypass graft; CVD, cerebrovascular disease; EF, ejection fraction.

Target DBT was achieved at a higher rate in smoker patients than in non-smoker patients $(\mathrm{n}=166$ [52.7\%] vs $\mathrm{n}=82[39.6 \%], \mathrm{p}<0.05)$. Patients with $\mathrm{DBT}<60$ min were younger than those with $\mathrm{DBT}>60$ min $(60 \pm 12,63 \pm 13, \mathrm{p}<0.05)$. Patients with a history of diabetes mellitus $(\mathrm{DM})$ have longer DBT than patients without DM $(\mathrm{n}=55[27.4 \%]$ vs $\mathrm{n}=63[19.6 \%], \mathrm{p}<0.05)$.

The relationship between the clinical experience level of emergency physicians and DBT is shown in Table 2 . The rate of current smokers is higher in the first group $(\mathrm{p}=0.028)$. Although the mean duration of DBT was lower in the emergency medicine specialist group, the rate of cardiogenic shock at the time of admission to the emergency and in-hospital mortality was higher in this group.

Table 2. Comparison of the experience level of emergency physicians on DBT and in-hospital outcomes.

\begin{tabular}{|c|c|c|c|c|}
\hline Parameters & $\begin{array}{l}\text { Medical practitioner } \\
(\mathrm{n}=351)\end{array}$ & $\begin{array}{l}\text { Assistant physician } \\
(\mathrm{n}=111)\end{array}$ & $\begin{array}{l}\text { Emergency } \\
\text { medicine specialist } \\
(\mathrm{n}=60)\end{array}$ & $\mathrm{p}$ \\
\hline Male, n (\%) & $282(80.3 \%)$ & $94(84.7 \%)$ & $47(78.3 \%)$ & 0.507 \\
\hline Female, n (\%) & $69(19.7 \%)$ & $17(15.3 \%)$ & $13(21.7 \%)$ & \\
\hline Age, years & $61.4 \pm 13.5$ & $60.0 \pm 13.4$ & $63.8 \pm 11$ & 0.385 \\
\hline $\begin{array}{l}\text { Current smoker, } \mathrm{n} \\
(\%)\end{array}$ & $177(50.4 \%)$ & $46(41.4 \%)$ & $25(41.7 \%)$ & 0.028 \\
\hline $\begin{array}{l}\text { Hypertension, } \mathrm{n} \\
(\%)\end{array}$ & $135(38.5 \%)$ & $49(44.1 \%)$ & $28(46.7 \%)$ & 0.340 \\
\hline $\begin{array}{l}\text { Diabetes mellitus, } \\
\mathrm{n}(\%)\end{array}$ & $74(21.1 \%)$ & $26(23.4 \%)$ & $18(30 \%)$ & 0.304 \\
\hline $\begin{array}{l}\text { Hyperlipidemia, n } \\
(\%)\end{array}$ & $45(12.8 \%)$ & $27(24.3 \%)$ & $8(13.3 \%)$ & 0.012 \\
\hline $\begin{array}{l}\text { CAD history, } \mathrm{n} \\
(\%)\end{array}$ & $57(16.2 \%)$ & $25(22.5 \%)$ & $12(22.5 \%)$ & 0.296 \\
\hline Prior stent, $\mathrm{n}(\%)$ & $38(10.8 \%)$ & $20(18 \%)$ & $7(11.7 \%)$ & 0.133 \\
\hline $\begin{array}{l}\text { Prior CABG, } \mathrm{n} \\
(\%)\end{array}$ & $9(2.6 \%)$ & $4(3.6 \%)$ & $5(8.3 \%)$ & 0.077 \\
\hline $\begin{array}{l}\text { CVD history, } \mathrm{n} \\
(\%)\end{array}$ & $8(2.3 \%)$ & $3(2.7 \%)$ & $3(5 \%)$ & 0.483 \\
\hline $\begin{array}{l}\text { Stent } \\
\text { implantation, } \mathrm{n} \\
(\%)\end{array}$ & $311(88.6 \%)$ & $95(85.6 \%)$ & $55(91.7 \%)$ & 0.476 \\
\hline SYNTAX score, $\mathrm{n}$ & $16.4 \pm 7.4$ & $15.8 \pm 6.3$ & $20.2 \pm 6$ & 0.373 \\
\hline $\mathrm{DBT}, \min$ & $80.8 \pm 82.1$ & $77.9 \pm 90.2$ & $53.1 \pm 38$ & 0.046 \\
\hline LBT, min & $19.6 \pm 10.8$ & $23.4 \pm 12.9$ & $23.5 \pm 13$ & 0.008 \\
\hline $\mathrm{EF} \%$ & $44.1 \pm 10.6$ & $43.2 \pm 9.7$ & $39.2 \pm 10$ & 0.001 \\
\hline $\begin{array}{l}\text { Recanalization, } \mathrm{n} \\
(\%)\end{array}$ & $59(16.8 \%)$ & $22(19.8 \%)$ & $6(10 \%)$ & 0.257 \\
\hline
\end{tabular}




\begin{tabular}{|c|c|c|c|c|}
\hline Parameters & $\begin{array}{l}\text { Medical practitioner } \\
(\mathrm{n}=351)\end{array}$ & $\begin{array}{l}\text { Assistant physician } \\
(\mathrm{n}=111)\end{array}$ & $\begin{array}{l}\text { Emergency } \\
\text { medicine specialist } \\
(\mathrm{n}=60)\end{array}$ & $\mathrm{p}$ \\
\hline $\begin{array}{l}\text { Arrhythmia, n } \\
(\%)\end{array}$ & $41(11.7 \%)$ & $10(9 \%)$ & $10(16.7 \%)$ & 0.331 \\
\hline $\begin{array}{l}\text { Renal injury, } \mathrm{n} \\
(\%)\end{array}$ & $20(5.7 \%)$ & $4(3.6 \%)$ & $2(3.3 \%)$ & 0.557 \\
\hline $\begin{array}{l}\text { Cardiogenic } \\
\text { shock, n (\%) }\end{array}$ & $32(9.1 \%)$ & $8(7.2 \%)$ & $17(28.3 \%)$ & $<0.001$ \\
\hline Exitus, n (\%) & $35(10.1 \%)$ & $5(4.5 \%)$ & $11(18.3 \%)$ & 0.014 \\
\hline
\end{tabular}

CAD , coronary artery disease; CABG , coronary artery bypass graft; CVD , cerebrovascular disease; DBT , door-to-balloon time; LBT , laboratory-to-balloon time;EF = ejection fraction.

\section{Discussion}

Treatment delays are the easiest controlled care quality index in STEMI. In hospitals and the emergency medical system, which are involved in the care of patients with STEMI patients, the aim is to reduce the delay between the emergency medical system and STEMI diagnosis to $10 \mathrm{~min}$.

Because delays in the treatment of myocardial infarction increase the likelihood and amount of myocardium damage due to localized hypoxia, DBT $<90 \mathrm{~min}$ is recommended [3]. Within the DBT targets published by the American Heart Association in 2006, it advocates seven basic evidence-based strategies to help reduce DBT [4]. One of these evidence-based strategiesis the experience of the emergency physician activating the angiography laboratory.

Comparing DBT $<60$ min with DBT $<90$ min, a $2.4 \%$ reduction in the 1-year absolute mortality risk reduction was achieved with DBT $<60$ min [5].Daniel et al. showed that over the years, as physician experience increased, the median DBT time decreased, and the percentage of those with DBT $<90$ min increased, but this did not contribute to in-hospital mortality [6]. The European Society of Cardiology recommends $\mathrm{DBT}<60 \mathrm{~min}$ if the patient is admitted to a primary center [7].Bradley et al. conducted a qualitative analysis of eleven hospitals with a mean DBT of $<90$ min in cases of myocardial infarction. As a result of this analysis, eight important criteria were determined in 11 hospitals, and the primary goal is reducing the DBT [8].Granger et al. emphasized the adequacy of the emergency room physician and listed the ideal primary PCI center criteria in his study (9). Kraft et al. reported that the rapid activation of the cardiac catheterization team and the interventional cardiologist by the emergency physician significantly reduces the DBT [10].It was concluded that a strategy mandating catheter laboratory activation by the emergency physician for STEMI without prior cardiology consultation lowers the DBT [11]. However, in this case, there may be unnecessary primary angiography procedures, and this may cause delays in the correct diagnosis of patients. Considering these studies, the relationship between the clinical experience level of emergency room staff and the duration of primary PCI in patients with acute STEMI is an important research problem.

In our study, the mean age was lower, the rate of smoking was higher, and the rate of patients with DM was lower in the group that reached the target DBT. This may be because elderly or patients with DM can have atypical symptoms. This can cause difficulty in diagnosis, resulting in prolonged DBT time. Emergency room physicians may suspect MI earlier when younger people and smokers apply to the emergency department with the complaint of chest pain.

Spontaneous coronary recanalization was more common in the DBT $>60$ min group, probably due to delay in the revascularization. The stent implantation rate in primary PCI procedure was higher in the DBT $<60$ min group. This may be likely because lesions that are difficult to revascularize have a longer procedure time and a higher failure rate. Because acute coronary revascularization was later in the DBT $>60$ min group, cardiogenic shock and death rates were higher, as expected. 
Our results showed that as the experience of emergency physicians increases, the mean DBT decreases. However, the mean ejection fraction and death rates were higher in this group. It is note worthy that the rate of cardiogenic shock during admission to the emergency department is quite high in this group compared with the other two groups. The fact that more experienced physicians attend to patients with worse clinical conditions in the emergency department, and even if the diagnosis-consultation-transportation-treatment period (DBT in summary) is shorter, the patients' current clinical condition is worse, which explains the higher death rate in this group.

Dan S et al shortened the "Physician In Triage" (PIT) team and other emergency unit teams in their study with 415 STEMI patients [12]. Their results showed that the 'door to catheter laboratory' and 'door to balloon time' were significantly lower in the groups evaluated by the PIT team. In addition, it was found that the patient group with a DBT time of $<90$ minutes was more in the group evaluated by the PIT team. These findings, which are consistent with our study results, are proof that experienced and specially trained units serving in the emergency department will contribute to shortening the duration of DBT. The fact that the PIT team, evaluated by the authors, did not work full-time in the emergency unit and that detailed information was not shared about the experience or expertise education levels of emergency physicians other than the PIT team are important limitations we observed in the study. For this reason, in our design, the fact that all physician groups working in the emergency unit are full-time, their experience / expertise levels are expressed in detail, and the relevant groups work at every stage of the emergency unit with the random rotation method increases the objectivity of our results.

In order to shorten the 'door to balloon time', clinicians have done many studies in different designs. One that draws attention among these is the design of Maliszewski B et al with a 1950 STEMI patient [13]. In their study, the authors kept patients who applied to the emergency department with the complaint of chest pain out of triage and marked them with a "red heart symbol" and directed them to ECG quickly. In their study where they compared the 'door to ECG' times before and after the application: The 'door to ECG' time was reduced to 7 minutes with the application of the "red heart symbol" of the clinic, whose "door to ECG' time was 17 minutes before the application. In accordance with the recommendations of the American Heart Association / American College of Cardiology guidelines, electrocardiography should be performed in less than 10 minutes in patients with chest pain in the emergency department, the percentage of the study patients with the 'door to ECG' times $<10$ minutes was increased to $83 \%$.

Noguchi M et al conducted with 239 STEMI patients; The studies in which they evaluated the effects of 'door to ECG', 'door to puncture' and 'puncture to balloon' times on the 'door to balloon' time support this success and publication of Maliszewski B et al [14]. In the study results of Noguchi $\mathrm{M}$ et al, it was found that the 'door to ECG', 'ECG to puncture', and 'pucture to balloon' times were significantly shorter in the group with a 'door to balloon' time $<90$ minutes (min) compared to the group with a 'door to balloon' time $>90$ minutes. In addition, the authors more strikingly as an independent risk factor in the prolongation of the 'door to balloon' time; They defined the 'door to ECG time $>10$ min', 'ECG to puncture time $>50$ min' and 'puncture to balloon time $>30$ min' parameters, and showed that the most effective parameter was the 'ECG to puncture time $>50$ min'. This result clearly shows the effects of the physicians working in the emergency unit on the 'door to balloon time', especially with the 'door to ECG' and 'EKG to puncture time' parameters. It has been proven by studies that the rapid ECG examinations of patients admitted to emergency units with chest pain and the rapid and accurate interpretation of these ECGs have serious effects on the 'door to balloon time'. In our study, our aim is to emphasize the importance of the experience and knowledge of physicians working in emergency units to manage the rapid diagnosis and treatment processes of STEMI patients.

\section{Conclusion}

If the DBT target value is not reached, in-hospital mortality increases. As the emergency physician experience level increases, the median DBT decreases, but we do not know whether this situation reflects on the clinical outcome due to other factors. Our study needs to be supported by prospective, randomized studies. 


\section{References}

1. Borja Ibanez, Stefan James, Stefan Agewall, , Alida L P Caforio et.al. The Task Force for the management of acute myocardial infarction in patients presenting with ST-segment elevation of the European Society of Cardiology (ESC). Eur Heart J 2018; 39(2): 119-177

2. NallamothuBK,BatesER. 2017 ESC guidelines for the management of acute coronary syndromes in patients presenting with persistent ST-segment elevation. Am J Cardiol 2003;92(7): 824-826

3.Elliott M Antman, Daniel T Anbe, et al. ACC/AHA 2007. Guidelines for the management of patients with ST-Elevation myocardial infarction archived June 26, at the Wayback Machine J Am CollCardiol 2004;44: 671-719.

4. John Brush, MD, (2007). "The D2B Alliance for Quality,"Archived 2007-08-09 at the Wayback machine STEMI SystemsIssue Two, May. Accessed July 2, 2007.

5. Park J, Choi KH, Lee JM, et al. Prognostic implications of door-to-balloon time and onset-to-door time on mortality in patients with ST-Segment-elevation myocardial infarction treated with primary percutaneous coronary intervention. Journal of the American Heart Association 2019;8(9): e012188. doi: 10.1161/JAHA.119.012188.

6. Menees DS, Peterson ED, Wang Y, et al. Door-to-balloon time and mortality among patients undergoing primary PCI. N Engl J Med 2013;369: 901-909.

7. Ibanez B, James S, Agewall S, et al. 2017 ESC Guidelines for the management of acute myocardial infarction in patients presenting with ST-segment elevation.European Heart Journal 2018;39: 119-177.

8. Bradley EH, Herrin J, Wang Y, et al. "Strategies for reducing the door-to-balloon time in acute myocardial infarction". N. Engl. J. Med 2006;355(22): 2308-20.

9. Granger C.B, Henry T.D, Bates W.E, et al. "Development of systems of care for ST-elevation myocardial infarction patients. The primary percutaneous coronary intervention (ST-elevation myocardial infarctionreceiving) hospital perspective". Circulation 2007;116(2): e55-9.

10. Kraft PL, Newman S, Hanson D, et al. Emergency physician discretion to activate the cardiac catheterization team decreases door-to-balloon time for acute ST-elevation myocardial infarction. Ann Emerg Med 2007;50(5): 520-6.

11. Jacoby J, Axelband J, Patterson J, et al. Cardiac cath lab activation by the emergency physician without prior consultation decreases door-to-balloon time. J Invasive Cardiol 2005; 17(3): 154-5.

12. Schwarzfuchs D, Shashar S, Sagy I, Novack V, Zeldetz V. Does the physician in triage strategy improve door-to-balloon time for patients with STEMI? Emerg Med J. 2020 Sep;37(9):540-545. doi: 10.1136/emermed-2019-209241. Epub 2020 Aug 4. PMID: 32753394.

13. Maliszewski B, Whalen M, Lindauer C, Williams K, Gardner H, Baptiste DL. Quality Improvement in the Emergency Department: A Project to Reduce Door-to-Electrocardiography Times for Patients Presenting With Chest Pain. J Emerg Nurs. 2020 Jul;46(4):497-504.e2. doi: 10.1016/j.jen.2020.03.004. Epub 2020 May 5. PMID: 32386775.

14. Noguchi M, Ako J, Morimoto T, Homma Y, Shiga T, Obunai K, Watanabe H. Modifiable factors associated with prolonged door to balloon time in patients with ST-segment elevation myocardial infarction undergoing primary percutaneous coronary intervention. Heart Vessels. 2018 Oct;33(10):1139-1148. doi: 10.1007/s00380-018-1164-y. Epub 2018 May 7. PMID: 29736558.

\section{Table Index:}

Table 1. Comparison of baseline characteristics and clinical outcomes of patients with or without DBT $<60$ min. 
Table 2. Comparison of the experience level of emergency physicians on DBT and in-hospital outcomes. Hosted file

Yeni Microsoft Office Word Belgesi.pdf available at https://authorea.com/users/387964/ articles/502840-relationship-between-door-to-balloon-time-and-clinical-experience-levelof-emergency-department-physicians 